\title{
A MATLAB-Based Application for Modeling and Simulation of Solar Slurry Photocatalytic Reactors for Environmental Applications
}

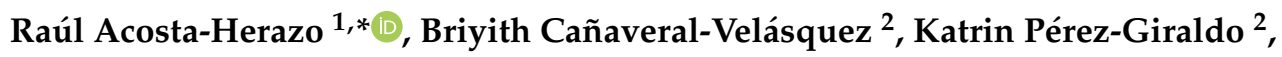 \\ Miguel A. Mueses ${ }^{2}{ }^{(1)}$, María H. Pinzón-Cárdenas ${ }^{1}$ and Fiderman Machuca-Martínez ${ }^{1}$ (i) \\ 1 School of Chemical Engineering, Universidad del Valle, Cali A.A. 25360, Colombia; \\ maria.pinzon@correounivalle.edu.co (M.H.P.-C.); fiderman.machuca@correounivalle.edu.co (F.M.-M.) \\ 2 Modeling and Applications of Advanced Oxidation Technologies Research Group, Photocatalysis and Solar \\ Photoreactors Engineering, Department of Chemical Engineering, Universidad de Cartagena, \\ Cartagena A.A. 1382-195, Colombia; briyithcarolina@hotmail.com (B.C.-V.); klpg_15@hotmail.com (K.P.-G.); \\ mmueses@unicartagena.edu.co (M.A.M.) \\ * Correspondence: raul.acosta@correounivalle.edu.co
}

Received: 2 July 2020; Accepted: 27 July 2020; Published: 4 August 2020

\begin{abstract}
Because of the complexity caused by photochemical reactions and radiation transport, accomplishing photoreactor modeling usually poses a barrier for young researchers or research works that focus on experimental developments, although it may be a crucial tool for reducing experimental efforts and carrying out a more comprehensive analysis of the results. This work presents PHOTOREAC, an open-access application developed in the graphical user interface of Matlab, which allows a user-friendly evaluation of the solar photoreactors operation. The app includes several solar photoreactor configurations and kinetics models as well as two variants of a radiation absorption-scattering model. Moreover, PHOTOREAC incorporates a database of 26 of experimental solar photodegradation datasets with a variety of operational conditions (model pollutants, photocatalyst concentrations, initial pollutant concentrations); additionally, users can introduce their new experimental data. The implementation of PHOTOREAC is presented using three example cases of solar photoreactor operation in which the impact of the operational parameters is explored, kinetic constants are estimated according to experimental data, and comparisons are made between the available models. Finally, the impact of the application on young researchers' projects in photocatalysis at the University of Cartagena was investigated. PHOTOREAC is available upon request from Professor Miguel Mueses.
\end{abstract}

Keywords: computer-based learning; solar photocatalysis; water contaminants; kinetic modeling; photoreactor design

\section{Introduction}

Heterogeneous photocatalysis is an example of an emerging environmental technology with a variety of promising applications, such as air and water disinfection and decontamination, clean fuel production and green product manufacturing [1-3].

Modeling and computer simulation of photoreactors are crucial for their design, scale-up and technology transfer; since they allow engineers and researchers to understand the role of the design parameters and operational conditions without performing an excessive number of experiments. However, modeling a solar photoreactor is a very complicated task, because it requires a combination of knowledge in applied solar energy, geometric optics, radiative transfer, materials science and photochemical reaction engineering. 
The implementation of commercial packages for photoreactor simulations is limited. Simulation packages for chemical plants, such as Aspen HYSYS ${ }^{\circledR}$ (Aspen Technology, Inc., Bedford, MA, USA) or Aspen plus ${ }^{\circledR}$ (Aspen Technology, Inc., Bedford, MA, USA), do not incorporate photocatalytic reactors. On the other hand, modeling and simulation of photoreactors can be carried out in Computational Fluid Dynamics (CFD) packages, such as COMSOL Multiphysics ${ }^{\circledR}$ (COMSOL, Inc., Burlington, MA, USA) and ANSYS ${ }^{\circledR}$ Fluent (ANSYS, Inc., Southpointe, PA, USA). However, they do not have modules dedicated to photoreactor engineering. Therefore, the simulations are performed by adapting the existing simulation modules for the simulation of photocatalytic reactors. This configuration of the CFD modules must be carried out manually by the user, which may result in an approach not intuitive enough for non-experts in photoreactor engineering. Another alternative is to perform the direct coding of the photoreactor model in a programming language. Still, this may result in a challenge for researchers that have not taken advanced courses in programming and numerical methods.

For the above reasons, the direct coding or the use of CFD simulators to implement a photoreactor model could be found inconvenient by non-expert researchers in photoreactors engineering, such as young researchers or those focused on experimental developments. However, implementing a photoreactor model may be a crucial tool for reducing the experimental efforts and carrying out a more comprehensive analysis of the results.

In this work, we present PHOTOREAC, an open-access computational application developed in the graphical user interface of Matlab wholly dedicated to the modeling and simulation of large-scale slurry solar photocatalytic reactors for environmental applications. It is based on the experience gathered by our research groups at Cartagena University (Cartagena de Indias, Colombia) and the Universidad del Valle (Cali, Colombia) during the last twenty years of research in heterogeneous solar photocatalysis, and also on extensive literature research in photoreactor engineering.

The application aims to provide non-expert researchers in photoreactors engineering a user-friendly, dedicated and efficient tool for the modeling and simulation of solar photoreactors, providing them with valuable information without implementing very sophisticated methods.

By employing PHOTOREAC, the users will be able to explore the role of critical parameters of the system on the radiation absorption performance of the photoreactor and the overall kinetic behavior of the photocatalytic process; parameters include the photoreactor geometry, the photoreactor dimensions, the model pollutant, the kinetic expression, the photocatalyst concentration, the photocatalysts optical properties, the initial pollutant concentration, the volume of treated water and the incident radiation. Additionally, PHOTOREAC incorporates a database of experimental information collected in our laboratory regarding the solar photodegradation of a variety of model pollutants under different operational conditions. Therefore, users will have empirical data available to carry out analyses and comparisons with their data.

\section{Solar Photoreactors Modeling by PHOTOREAC}

PHOTOREAC performs the modeling and simulation of the photoreactors following the general algorithm described in Figure 1. The algorithm considers mathematical simplifications to maintain the approach as rigorously and computationally efficient as possible, and thus it provides the users with valuable information without implementing sophisticated numerical methods that, although they can improve the quantitative results, may not affect the qualitative analysis. These assumptions and simplifications will be described and discussed in the upcoming sections.

The basis of the PHOTOREAC approach is that the radiation field modeling can be carried out independently of the photocatalytic kinetics modeling since the radiation balance in the photoreactor is not a function of the concentration of the chemical species. Therefore, the radiation balance is decoupled from the mass and momentum balances of the system. Besides, the radiation field described by the local volumetric rate of photon absorption (LVRPA) profile inside the photoreactor is considered to be in a steady-state, i.e., it does not vary along the reaction rime its reaction time does not change $[4,5]$. On the other hand, to carry out a kinetic analysis independent of the radiation absorption effects, 
i.e., the optimized kinetic parameters are not a function of the irradiation conditions, it is mandatory to know the radiation field in the photoreactor beforehand [6,7].

Thus, PHOTOREAC considers two modules: (i) the photon absorption-scattering module, in which the user will be able to determine the radiation field of the available photoreactor configurations by following the procedure described by the red box in Figure 1; and (ii) the kinetic modeling module, in which the user will be able to estimate the radiation-independent kinetic parameters for the four available kinetics expressions following the procedure described in the blue box in Figure 1.

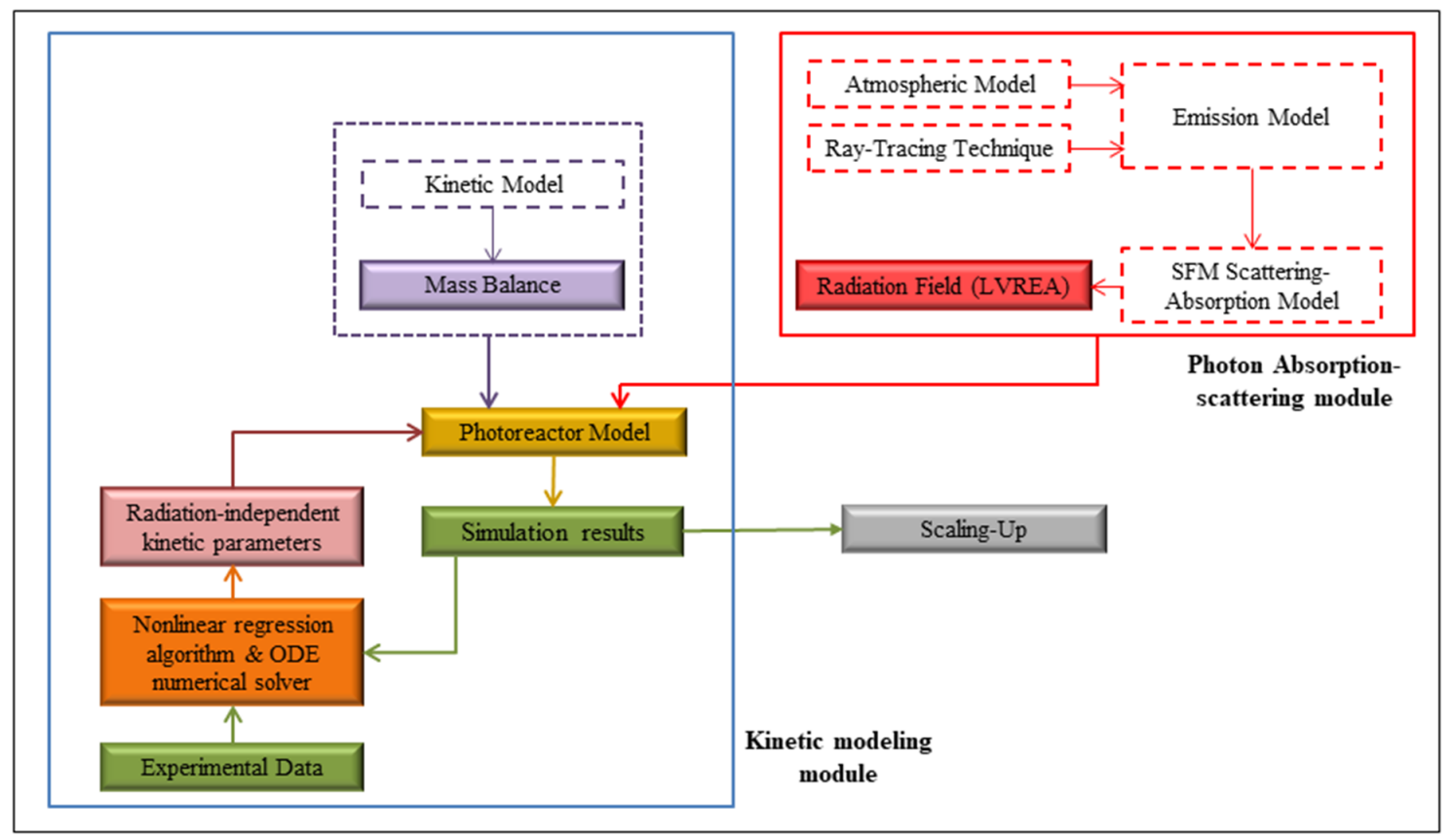

Figure 1. General algorithm for the modeling and simulation of solar slurry photoreactors in PHOTOREAC. ODE: Ordinary Differential Equation; SFM: Six Flux Model.

\subsection{The Photoreactors Set-Up in PHOTOREAC}

PHOTOREAC includes three configurations of pilot-scale solar photoreactors: a flat plate photoreactor (FPP), a compound parabolic collector photoreactor (CPCP) and a tubular-type photoreactor (TTP). These are the most common configurations for solar-pilot applications of heterogeneous photocatalysis; a detailed description of them can be found in the literature $[3,8,9]$. For the TTP, a novel prototype is also included, the offset multi-tubular photoreactor (OMTP) [10]. All of the photoreactors operate in recirculation, a flow-through mode with the water passing through an external tank, as shown in Figure 2. The photoreactor is exposed to the sunlight, facing the sun, while the reservoir tank is in the dark. The flow consists of an aqueous suspension of photocatalyst powder and the dissolved contaminant. The Evonik $\mathrm{TiO}_{2} \mathrm{P} 25$ was selected as the model photocatalyst in PHOTOREAC because it is considered the most promising alternative for commercial applications due to its low cost, photochemical stability, and high oxidation power [3]. Therefore, it is widely studied, and its physicochemical and optical properties are well known in the literature [11]. 


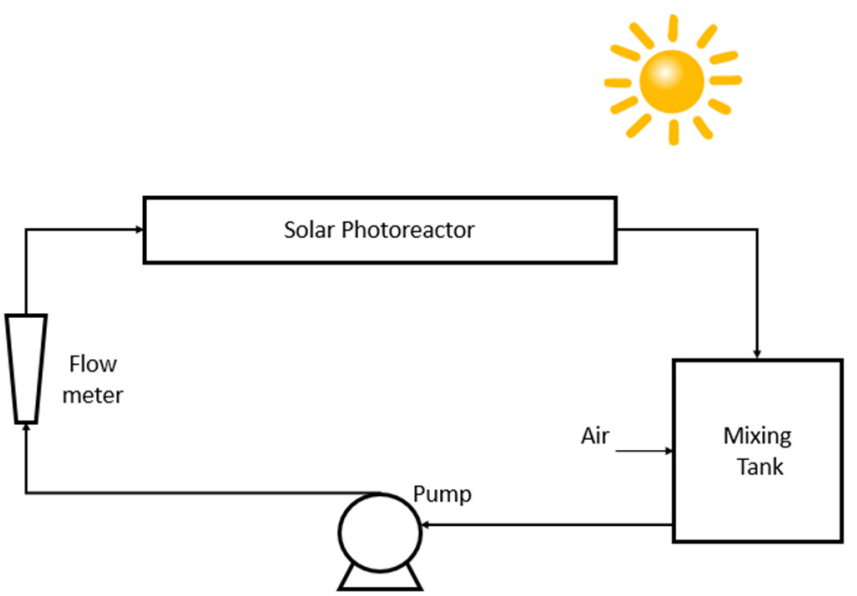

Figure 2. Scheme of a solar pilot photoreactor set-up.

\subsection{The Input Data for the Use of PHOTOREAC}

The availability and reliability of the input data provided to PHOTOREAC are crucial for good results. Table 1 shows a summary of the input information that is required to simulate the photoreactors in PHOTOREAC. Additionally, it is indicated in which module is the information used.

Table 1. Summary of the input information for the PHOTOREAC modules.

\begin{tabular}{cccc}
\hline Parameter & Symbol & Units & $\begin{array}{c}\text { Belonging to } \\
\text { PHOTOREAC Module }{ }^{\text {a }}\end{array}$ \\
\hline Photoreactor radius (CPCP and OMTP) & $R$ & $\mathrm{~m}$ & PASM \\
Water film thickness (FFP) & $\delta$ & $\mathrm{m}$ & PASM \\
Photoreactor length & $L$ & $\mathrm{~m}$ & PASM \\
Solar incident radiation & $I_{0}$ & $\mathrm{~W} / \mathrm{m}^{2}$ & PASM \\
Reaction volume & $V_{R}$ & $\mathrm{~L}$ & PASM/KMM \\
Photocatalyst concentration & $C_{\text {cat }}$ & $\mathrm{g} / \mathrm{L}$ & PASM/KMM \\
Total volume & $V_{T}$ & $\mathrm{~L}$ & $\mathrm{KMM}$ \\
Number of experimental photodegradation data & $N$ & Dimensionless & $\mathrm{KMM}$ \\
Concentration vs. accumulated energy data $\mathrm{b}$ & $C_{i}$ vs. $\xi_{A E}$ & ppm vs. J/m ${ }^{2}$ & $\mathrm{KMM}$ \\
Concentration vs. standard time data ${ }^{\mathrm{b}}$ & $C_{i}$ vs. $t$ & $\mathrm{ppm}$ vs. min & $\mathrm{KMM}$ \\
\hline
\end{tabular}

${ }^{a}$ PASM: photon absorption-scattering module; KMM: kinetic modeling module. ${ }^{\mathrm{b}}$ If it is a multicomponent mixture, $C_{i}$ is replaced by TOC.

At the same time, the experimental photodegradation data for kinetic analysis in PHOTOREAC deserves special attention. The effects of the adsorption must be carefully considered in the solar photocatalytic experimental test. The photodegradation data used to feed PHOTOREAC must be reported at the zero-point of photodegradation, where adsorption has already been allowed to homogenize, which is usually achieved by allowing the system to recirculate under darkness for $30 \mathrm{~min}$ to establish adsorption-desorption equilibrium conditions before being exposed to solar light. Thus, although the kinetic models in PHOTOREAC do not contemplate the competitive effects of molecular adsorption, the data used will already be corrected with that effect. Therefore, there is no problem with the application of the models [10,12].

During the exposure time to sunlight, the data should be reported as the pollutant concentration $C_{i}$ against the accumulated ultraviolet (UV) energy $\xi_{A E}$. The experiments finish when the desired accumulated UV total energy in $\mathrm{J} / \mathrm{m}^{2}$ is reached. Additionally, it is required to record the corresponding standard time for each sample. 


\subsection{The PHOTOREAC Photon Absorption-Scattering Module}

The PHOTOREAC photon absorption-scattering module performs the radiation field modeling of the three available configurations of solar photoreactors: FPP, CPCP and OMTP. It provides the LVRPA spatial distribution inside the photoreactor and the overall volumetric rate of photon absorption (OVRPA), which corresponds to the LVRPA averaged over the entire volume of the reactor. The latter is a critical magnitude for the kinetic assessment [12].

The PHOTOREAC modeling approach is focused on the six-flux absorption-scattering model (SFM). SFM is an analytical equation in which the leading hypothesis is that scattering only occurs in the six Cartesian directions [5]. Despite being a simplified model, it retains the key aspects of the radiation field modeling in photoreactors and has been implemented successfully at the solar pilot scale $[13,14]$. Other modeling approaches for solar photoreactors, such as the discrete ordinate method (DOM) or the Monte Carlo simulation, offer a more accurate description of the radiation transport phenomena. However, they are more time-consuming in the computations and their mathematical formulation is of high complexity. The SFM short computation times are ideal for exploring the impact of operational parameters, including the photocatalyst concentration, photoreactor dimensions and incident radiation, in particular for users that are dabbling in photoreactor engineering, to which PHOTOREAC is oriented. Independently of the photoreactor configuration, the central equation of SFM is given by [14]:

$$
\operatorname{LVRPA}=\frac{I_{0}}{\lambda_{\omega_{\text {corr }} \omega_{\text {corr }}(1-\gamma)}}\left[\left(\omega_{\text {corr }}-1+\sqrt{1-\omega_{\text {corr }}^{2}}\right) e^{-\frac{r p}{\lambda_{\omega_{c o r r}}}}+\gamma\left(\omega_{\text {corr }}-1-\sqrt{1-\omega_{\text {corr }}^{2}}\right) e^{\frac{r_{p}}{\lambda_{\omega c o r r}}}\right]
$$

where $I_{0}$ is the incident solar radiation in $\mathrm{W} / \mathrm{m}^{2}$ and $r_{p}$ is a spatial coordinate in the reactor domain whose definition depends on the reactor geometry. Finally, the corrected photon path length $\lambda_{\omega c o r r}$ in $\mathrm{m}$, the dimensionless corrected scattering albedo $\omega_{\text {corr }}$ and the dimensionless parameter $\gamma$ are all parameters derived from the SFM formulation. PHOTOREAC also includes a more recent variant of the SFM, the Six Flux Model coupled to the Henyey-Greenstein scattering phase function (SFM-HG). In it, the Henyey-Greenstein (HG) scattering phase function is used to describe the optical properties of the $\mathrm{TiO}_{2} \mathrm{P} 25$ photocatalyst. By contrast, the SFM describes $\mathrm{TiO}_{2}$ based on a diffuse reflectance scattering phase function [15]. By incorporating both variants of SFM, the users will be able to observe the role of the scattering phase function. The parameters and implementation of Equation (1) are detailed in the literature, and the modeling details for the FFP are given in previous work [16].

On the other hand, for the CPCP and the OMTP, a ray-tracing technique together with Equation (1) must be implemented, since, besides the incident radiation, the direction with which solar rays impact the photoreactor is crucial. A complete description of the SFM implementation for CPCP and OMTP is reported elsewhere $[10,13,14]$.

\subsection{The PHOTOREAC Kinetic Modeling Module}

The PHOTOREAC kinetic modeling module estimates the kinetic parameters from the photodegradation experimental data provided. Table 2 shows the photocatalytic kinetic models in PHOTOREAC. These models explicitly consider the effect of the radiation absorption on the average reaction rate in $\left\langle-r_{i}\right\rangle_{V_{R}}$ by including the $E_{g}$, and the overall rate of photon absorption (OVRPA) in $\mathrm{W} / \mathrm{m}^{3}$, which corresponds to the LVRPA averaged over the entire volume of the reactor. Additionally, $C_{i}$ is the concentration of the water contaminant in $\mathrm{mol} / \mathrm{m}^{3}, \kappa_{P}=2 / S_{g} C_{c a t}$ is the particle constant in $\mathrm{m}^{3} / \mathrm{m}^{2}, S_{g}$ is the catalyst specific surface area $\mathrm{m}^{2} / \mathrm{kg}, C_{C a t}$ is the photocatalyst concentration $\mathrm{kg} / \mathrm{m}^{3}$, $\mathrm{C}_{\mathrm{O} 2}$ is the oxygen concentration in $\mathrm{mol} / \mathrm{m}^{3}$ and $\phi_{g}^{\text {eff }}$ is the effective quantum yield in $\mathrm{mol} /(\mathrm{s}$ watts). Finally, $k^{L-H}, K_{k i n}, \alpha_{1}$ and $\alpha_{2}$ are the kinetic constants of the models, which are independent of the irradiation conditions. 
Table 2. Photocatalytic kinetic models in PHOTOREAC.

\begin{tabular}{|c|c|c|c|}
\hline Kinetic Model & Mathematical Expression & Fitting Parameters & Refs. \\
\hline Langmuir-Hinshelwood & $\left\langle-r_{i}\right\rangle_{V_{R}}=-\frac{K_{K i n} k^{L-H} C_{i}}{1+k^{L-H} C_{i}}\left(E_{g}\right)^{0.5}$ & $\begin{array}{c}k^{L-H}(\mathrm{~L} / \mathrm{mol}), K_{k i n}(\mathrm{~mol} \\
\left.\mathrm{L}^{-1} \mathrm{~s}^{-1} \mathrm{~W}^{-0.5}\right)\end{array}$ & [13] \\
\hline Zalazar et al. & $\left\langle-r_{i}\right\rangle_{V_{R}}=-\frac{\phi_{g}^{e f f} E_{g}}{\frac{1}{2}+\left[\frac{1}{4}+K_{k i n} \frac{\phi_{g}^{e f f} E_{g}}{2 C_{c a t}^{2} C_{i} C_{O_{2}}}\right]^{0.5}}$ & $\begin{array}{l}\phi_{g}^{\text {eff }}\left(\mathrm{mol} \mathrm{s}^{-1} \text { watts }^{-1}\right), \\
K_{\text {kin }}\left(\text { mole s kg }^{2} \mathrm{~m}^{-9}\right)\end{array}$ & [17] \\
\hline Ballari et al. & $\left\langle-r_{i}\right\rangle_{V_{R}}=-2 \frac{\alpha_{1}}{\kappa_{p}}\left[-1+\sqrt{1+\kappa_{P} \frac{\alpha_{2} E_{g}}{C_{i}}}\right] C_{i}$ & $\begin{array}{l}\alpha_{1}\left(\mathrm{~cm} \mathrm{~s}^{-1}\right), \alpha_{2}(\mathrm{~mol} \\
\left.\text { watts }^{-1} \mathrm{~cm}^{-1}\right)\end{array}$ & {$[18]$} \\
\hline Mueses et al. & $\left\langle-r_{i}\right\rangle_{V_{R}}=-2 \frac{\alpha_{1}}{\kappa_{P}}\left[-1+\sqrt{1+\frac{\kappa_{p}}{\alpha_{1}} \phi_{g}^{e f f} E_{g}}\right] \frac{k^{L-H} C_{i}}{1+k^{L-H} C_{i}}$ & $\begin{array}{c}\alpha_{1}\left(\mathrm{~mol} \mathrm{~m}^{-2} \mathrm{~s}^{-1}\right), \phi_{g}^{e f f} \\
\left(\mathrm{~mol} \mathrm{~s}^{-1} \mathrm{watts}^{-1}\right) \\
k^{L-H}\left(\mathrm{~m}^{3} \mathrm{~mol}^{-1}\right)\end{array}$ & [12] \\
\hline
\end{tabular}

Each of these previous expressions has its features and limitations, from either a phenomenological or a numerical point of view. For instance, the Langmuir-Hinshelwood expression is a semi-empirical model. By contrast, the other models were deduced from a detailed reaction mechanism. Zalazar et al. and Mueses et al.'s kinetic expressions consider the effect of the effective quantum yield $\phi_{g}^{\text {eff }}$ explicitly, a critical parameter to evaluate photocatalytic reactions. However, the expression proposed by Mueses et al. is the only one with three fitting parameters, unless the effective quantum yield of the system is previously known [12].

To determine the kinetics parameters, it is necessary to follow a rigorous approach to account for the effects of the diffusion and convection in the material balance of the photoreactor. Although the inclusion of these effects will provide more accurate results for the kinetic parameters (such parameters will be independent of the diffusion and convection), it also implies the implementation of more advanced numerical techniques, e.g., finite differences and orthogonal collocation $[7,19]$. PHOTOREAC considers the photoreactor-tank system as a batch mode reactor; therefore, the effects of the diffusion and convection are lumped in the kinetic parameters, which simplifies the numerical approach.

The following assumptions are established for the mass balance of the system (represented by Figure 2): (i) the system is perfectly mixed; (ii) there are no mass transport limitations; (iii) the conversion per pass in the reactor is differential; and (iv) parallel dark reactions can be neglected. The mass balance in the reservoir tank can then be expressed as follows [7,18]:

$$
\frac{d C_{i}}{d t}=\frac{V_{R}}{V_{T}}\left\langle-r_{i}\right\rangle_{V_{R}}
$$

where $C_{i}$ is the concentration of the water contaminant in $\mathrm{mol} / \mathrm{m}^{3}$ at time $t, t$ is time in $\mathrm{s},\left\langle-r_{i}\right\rangle_{V_{R}}$ is the average reaction rate in $\left(\mathrm{mol} \mathrm{m}^{3} \mathrm{~s}^{-1}\right)$, and $V_{R}$ and $V_{T}$ are the volumes of the photoreactor and the total reaction volume in $\mathrm{m}^{3}$, respectively. However, for solar photoreactors, the standard time may not be the more appropriate magnitude for following the concentration of the water pollutant due to the fluctuation of the incident solar irradiance because of the atmospheric phenomena and the time of day. Therefore, a change of variable is proposed as follows [10]:

$$
\begin{gathered}
\frac{d C_{i}}{d t}=\left(\frac{d C_{i}}{d \xi_{A E}}\right)\left(\frac{d \xi_{A E}}{d t}\right) \\
\frac{d C_{i}}{d \xi_{A E}}=\frac{\beta}{\xi_{t}}\left\langle-r_{i}\right\rangle_{V_{R}}
\end{gathered}
$$

With the initial condition, $C_{i}\left(\xi_{A E}=0\right)=C_{i, 0}$, where $C_{i}$ is the water contaminant concentration for a given $\xi_{A E}$ is the accumulated energy in $\mathrm{J} / \mathrm{m}^{2}, \xi_{t}=\left(\frac{d \xi_{A E}}{d t}\right)$ in $\mathrm{J} / \mathrm{m}^{2} \mathrm{~s}$ is the slope of the straight line resulting from the experimental data relationship of the accumulative incident solar radiation vs. time for each experimental test, and the dimensionless factor $\beta=V_{R} / V_{T}$. 
The search for the best values for the kinetic parameters of the model is carried out using a non-linear regression procedure, as is shown in Figure 1. It starts with an initial guess and follows an optimization criterion until the required convergence is reached. The error function is given by the sum of the squared errors of the experimental water contaminant concentration $C_{i, \exp }$ and the value determined from the numerical solution of Equation (4) $C_{i, c a l c}$ :

$$
F_{o b j}=\sum_{i=1}^{N}\left(C_{i, \exp }-C_{i, c a l c}\right)^{2}
$$

where $N$ is the number of experimental data. The Matlab function fminsearch, which uses the Nelder-Mead algorithm, is implemented as the optimization solver together with the Matlab function ode 45 for solving the ordinary differential equation (ODE) given by Equation (4).

For the photodegradation of multicomponent mixtures, the concentration $C_{i}$ may be replaced by a global concentration parameter such as total organic carbon (TOC) [12]. Therefore, Equation (4) is written as:

$$
\frac{d T O C}{d \xi_{A E}}=\frac{\beta}{\xi_{t}}\left\langle-r_{T O C}\right\rangle_{V_{R}}
$$

with the initial condition $T O C\left(\xi_{A E}=0\right)=T O C_{0}$, where TOC is the total organic carbon of the mixture $\mathrm{mol} / \mathrm{m}^{3}$ for a given $\xi_{A E}, \xi_{A E}$ is the accumulated energy in $\mathrm{J} / \mathrm{m}^{2}, T O C_{0}$ is TOC of the mixture measured at the starting point of the experiment, and $V_{R}$ and $V_{T}$ are the volumes of the photoreactor and the total reaction volume in $\mathrm{m}^{3}$, respectively. $\left\langle-r_{T O C}\right\rangle_{V_{R}}$ is the average reaction rate of the TOC of the mixture in $\left(\mathrm{mol} \mathrm{m} \mathrm{s}^{-1}\right)$. The mathematical expressions for $\left\langle-r_{T O C}\right\rangle_{V_{R}}$ are the same given in Table 2, replacing $\left\langle-r_{i}\right\rangle_{V_{R}}$ by $\left\langle-r_{T O C}\right\rangle_{V_{R}}$ and $C_{i}$ by TOC.

Similarly, Equation (5) is rewritten as:

$$
F_{o b j}=\sum_{i=1}^{N}\left(T O C_{i, \exp }-T_{O C}, \text { calc }\right)^{2}
$$

Then, for multicomponent mixtures, the TOC of the mixture must be provided to PHOTOREAC as a function of the accumulated energy instead of the concentration of a pure component water contaminant. This approach is particularly useful in real environmental applications because in such cases the most usual situation is that the content of the wastewater is unknown, and it would be tough and resource-consuming to determine it. Therefore, it is easier to establish a global parameter such as the TOC, which shows the mineralization of both intermediates and the precursor compounds in the wastewater. By contrast, the monitoring of each initial pure component in the mixture does not consider the formation of intermediates.

The Kinetic Modeling Module Database

In the kinetic modeling module, PHOTOREAC incorporates a database that consists of 26 datasets of the solar photocatalytic degradation of water contaminants using $\mathrm{TiO}_{2} \mathrm{P} 25$ Evonik as a photocatalyst. The information was collected by the Modeling and Applications of Advanced Oxidation Technologies Research Group at Cartagena University (Cartagena de Indias, Colombia) and the Research Group on Advanced Processes for Biological and Chemical Treatments (GAOX) at the Universidad del Valle (Cali, Colombia). Table 3 details the information available in the database: two solar photoreactor configurations (CPCP and OMTP) and five model pollutants at different initial concentrations and photocatalyst concentrations. By selecting the dataset to perform the kinetic analysis, PHOTOREAC loads the information about the experimental test: the pollutant concentration vs. accumulated energy data, the OVRPA and the $\beta=V_{R} / V_{T}$ factor. 
Table 3. PHOTOREAC database of the solar photodegradation of water contaminants.

\begin{tabular}{cccc}
\hline Water Contaminant & $\begin{array}{c}\text { Photoreactor } \\
\text { Configuration }\end{array}$ & $\begin{array}{c}\text { Initial Concentration of } \\
\text { the Contaminant, ppm }\end{array}$ & $\begin{array}{c}\text { Photocatalyst } \\
\text { Concentration, } \mathbf{g} / \mathbf{L}\end{array}$ \\
\hline \multirow{2}{*}{$\begin{array}{c}\text { Dichloroacetic acid } \\
\text { (DCA) }\end{array}$} & CPCP & 30 & $0.1,0.5$ \\
& OMTP & 60 & $0.1,0.35$ \\
& CPCP & 120 & $0.1,0.35,0.5$ \\
\hline \multirow{2}{*}{ Phenol (PH) } & OMTP & 60 & 0.35 \\
\cline { 2 - 4 } & \multirow{2}{*}{ CPCP } & 60 & 0.35 \\
\hline \multirow{2}{*}{ 4-chlorophenol (4-CP) } & OMTP & 120 & 0.1 \\
\cline { 2 - 4 } & CPCP & 60 & 0.1 \\
\hline \multirow{2}{*}{ Methylene Blue (MB) } & OMTP & 120 & 0.1 \\
\cline { 2 - 4 } & CPCP & 60 & 0.1 \\
\hline Amoxicillin (AMX) & & 120 & 0.5 \\
\hline
\end{tabular}

\section{Implementation of PHOTOREAC in Solar Photoreactors}

In this section, three example cases to demonstrate the use of the PHOTOREAC application are presented. All of the cases are based on an experimental test already performed in the solar photoreactor platforms of our research groups in Cartagena, Colombia $\left(10^{\circ} 25^{\prime} 25^{\prime \prime} \mathrm{N}, 75^{\circ} 31^{\prime} 31^{\prime \prime} \mathrm{W}\right)$ and Cali, Colombia $\left(3^{\circ} 27^{\prime} 00^{\prime \prime} \mathrm{N}, 76^{\circ} 32^{\prime} 00^{\prime \prime} \mathrm{W}\right)$. Further information about the set-up and operation of the experimental solar tests can be found in previous works [10,12].

\subsection{Example Case I: Solar Photodegradation of Dichloroacetic Acid (DCA) in a CPCP}

This example shows the implementation of PHOTOREAC for an analysis of the solar photocatalytic degradation of DCA in a CPCP. The photoreactor consists of ten borosilicate tubes with radius $R=$ $0.016 \mathrm{~m}$ and length $L=1.2 \mathrm{~m}$ providing a reaction volume of $V_{R}=9.7 \mathrm{~L}$. The DCA initial concentration was $C_{i}=30$ ppm using a $\mathrm{TiO}_{2} \mathrm{P}_{2} 5$ Evonik concentration of $C_{c a t}=0.5 \mathrm{~g} / \mathrm{L}$. The main objective of the example case was to determine the radiation-independent kinetic parameters of the system from the experimental data provided to the application using the SFM as the radiative model.

First, the radiation field is determined by the photon absorption-scattering module. Figure 3 shows the main screen of the PHOTOREAC GUI: (1) the photoreactor panel, where the photoreactor configuration was selected; (2) the system properties panel, where the input data were introduced for the simulation; (3) the SFM model panel, where the SFM variant for the simulation is selected; (4) the SFM scattering phase function probabilities are displayed according to the SFM variant that was selected, in this case, the SFM; (5) the resulting LVRPA spatial distribution in the cross-section of the CPCP tube is plotted; (6) the resulting OVRPA of the system is displayed; (7) the options menu. Together with the main screen shown in Figure 3, PHOTOREAC generates a secondary screen with the results of the ray-tracing simulation (Figure 4). 


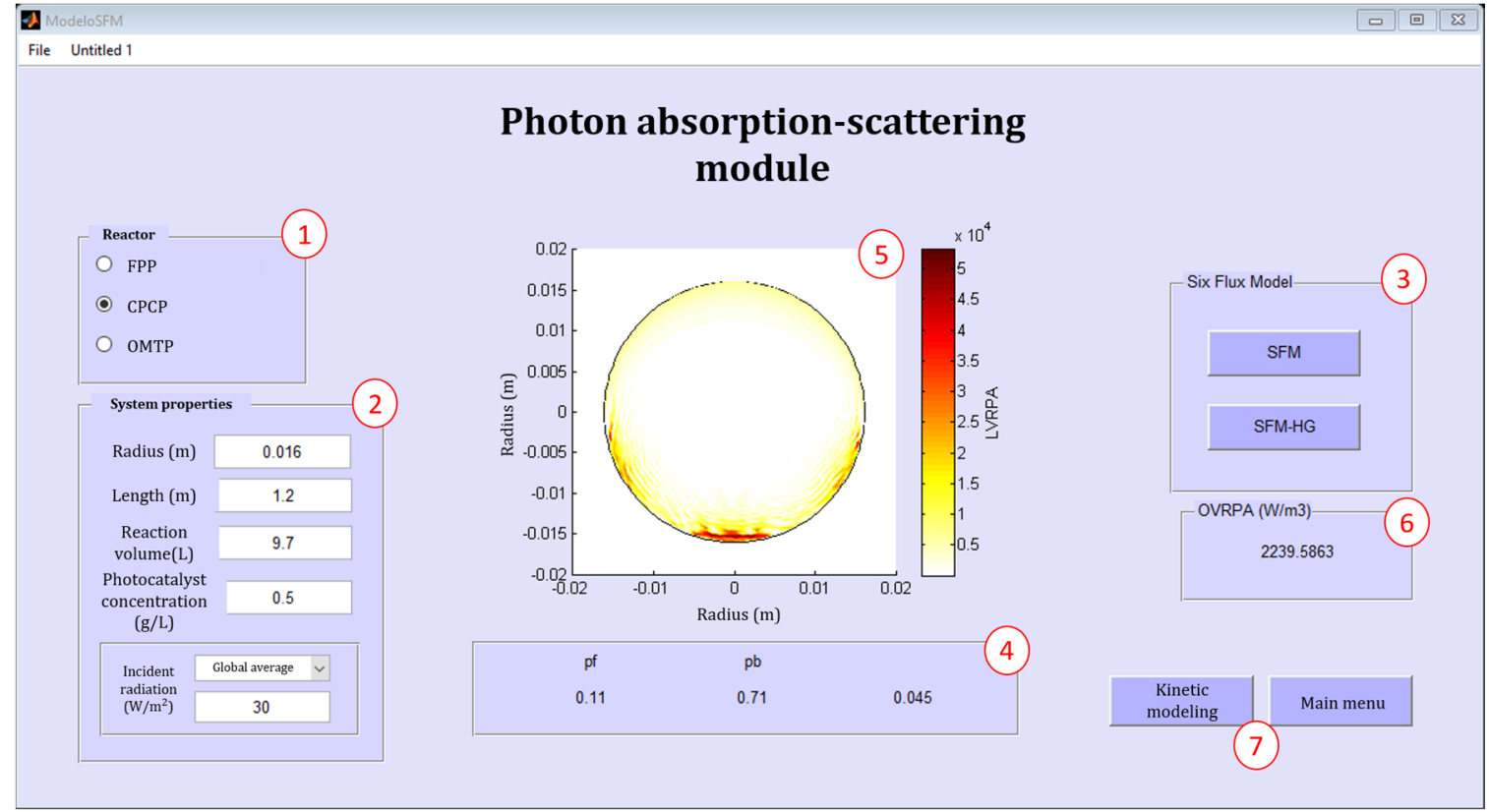

Figure 3. Radiation field simulation for a CPCP in the photon absorption-scattering module. (1) photoreactor panel; (2) system properties panel; (3) the SFM panel; (4) display the corresponding SFM scattering probabilities used in the simulation; (5) LVRPA spatial distribution plot; (6) OVRPA; (7) options menu.

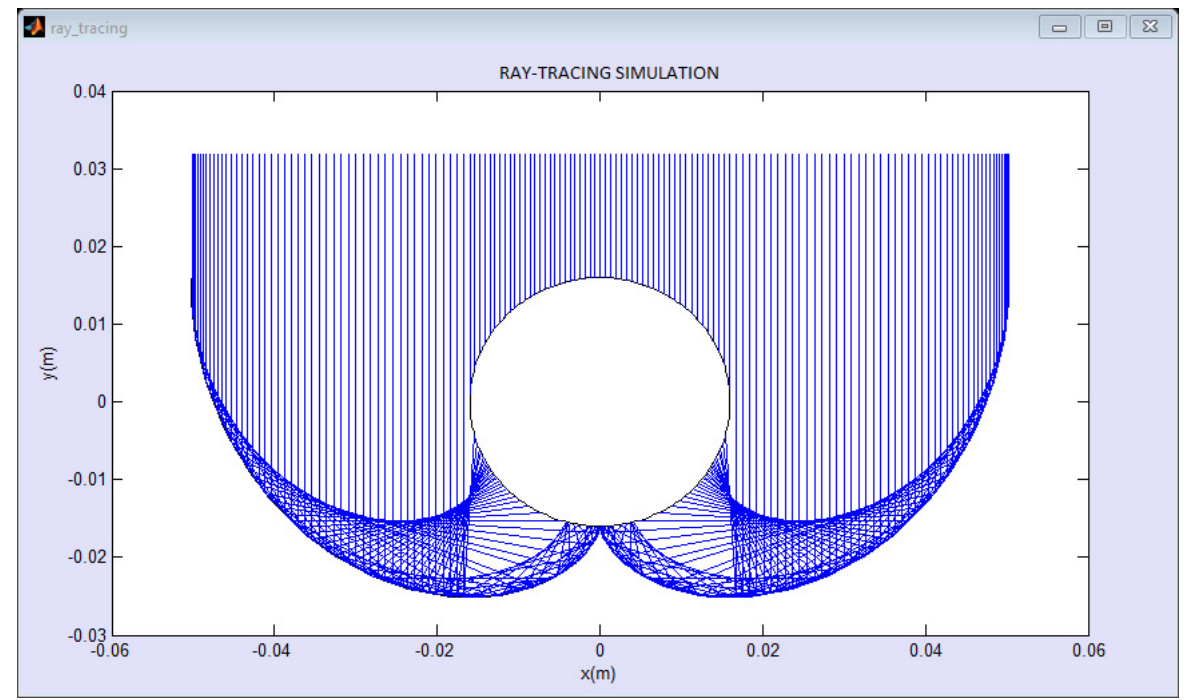

Figure 4. Ray-tracing simulation for the CPCP.

From the results presented by the photon absorption-scattering module, the user will be able to extract essential findings regarding the impact of variables on the photocatalyst concentration. For instance, for this example case, in the LVRPA distribution plot shown in Figure 3, it is observed that the highest values of the LVRPA are around $y=-0.015 \mathrm{~m}$ and $y=-0.005 \mathrm{~m}$. This result is due to the fact that at these coordinates there is a high concentration of rays that come from the CPCP reflectors, as can be observed in Figure 4. Additionally, it is observed that the LVRPA is concentrated near to the CPCP wall, and the center of the tube shows very low LVRPA values, as a result of the relatively high photocatalyst concentration used in the simulation $\left(C_{c a t}=0.5 \mathrm{~g} / \mathrm{L}\right)$. This behavior is well-known in the literature: at high concentrations of the photocatalyst, the photons cannot penetrate deeply into the tube and the absorbed energy is concentrated around the boundary wall [14]. 
Once the radiation field for the CPCP is determined, the application proceeds to the kinetic modeling module. Figure 5 shows the input panel displayed by PHOTOREAC. The application loads the system parameters determined previously, such as the $\mathrm{TiO}_{2}$ concentration and the OVRPA. The remaining system parameters must be provided manually by the user. Similarly, the photodegradation vs. accumulated energy data should be introduced in the experimental data panel. Finally, the user may proceed to the kinetic modeling module's main screen.

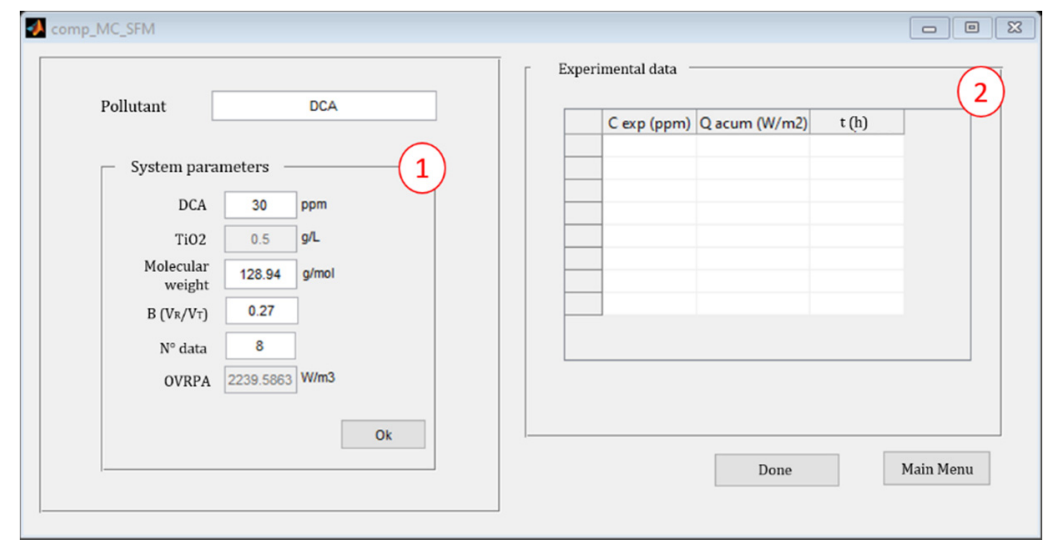

Figure 5. Input panel for the kinetic modeling module. (1) System parameters panel; (2) experimental data panel.

Figure 6 shows the main screen of the PHOTOREAC GUI at the kinetic modeling module: (1) kinetic models panel, where the user can choose the kinetic models to be fitted; (2) experimental data and models simulations plot, where the experimental data and the fitting curves of the models that were previously selected are displayed; (3) fitted kinetic parameters panel, where the values of the fitting parameters of each model chosen are displayed; (4) the $x$-axis magnitude panel, where the user can determine if the displayed data are presented in accumulated energy or standard time as the $x$-axis magnitude; (5) correlation coefficient panel, which displays the higher $R^{2}$ among the selected kinetic models; (6) correlation coefficient panel, which shows the kinetic model with the highest $R^{2}$ value among the chosen ones; (7) export data button, which exports the results of the fitting curve to a Microsoft Excel file; (8) options menu panel.

From the PHOTOREAC kinetic modeling module screen in Figure 6, it is observed that the best fitting is achieved for the Ballari et al. model with $R^{2}=0.97392$. The other models reported $R^{2}=0.97365$ for Mueses et al., $R^{2}=0.63843$ for Langmuir-Hinshelwood and $R^{2}=0.63585$ for Zalasar et al. Due to PHOTOREAC only displaying the model with the higher value for the correlation coefficient $R^{2}$, it selected the Ballari et al. model. However, Mueses et al.'s expression showed an almost identical $R^{2}$, and it should not be discarded without further analysis. From Table 2, it is observed that the mathematical structure of the Ballari et al. and Mueses et al. expressions are very similar; indeed, the Ballari et al. expression is considered a particular case of the Mueses et al. model for systems with high molecular adsorption [12]. Therefore, it is expected that both models performed similarly, as is the case for the DCA photodegradation. The Langmuir-Hinshelwood and Zalasar et al. expressions may not lead to successful results due to the fact that they do not describe the effects of the absorbed radiation (OVRPA) accurately. On the other hand, Ballari et al. and Mueses et al. may perform better since they include an OVRPA squared root correction factor. the same can be said for Ballari et al. and Mueses et al. regarding the OVRPA squared root correction factor. 


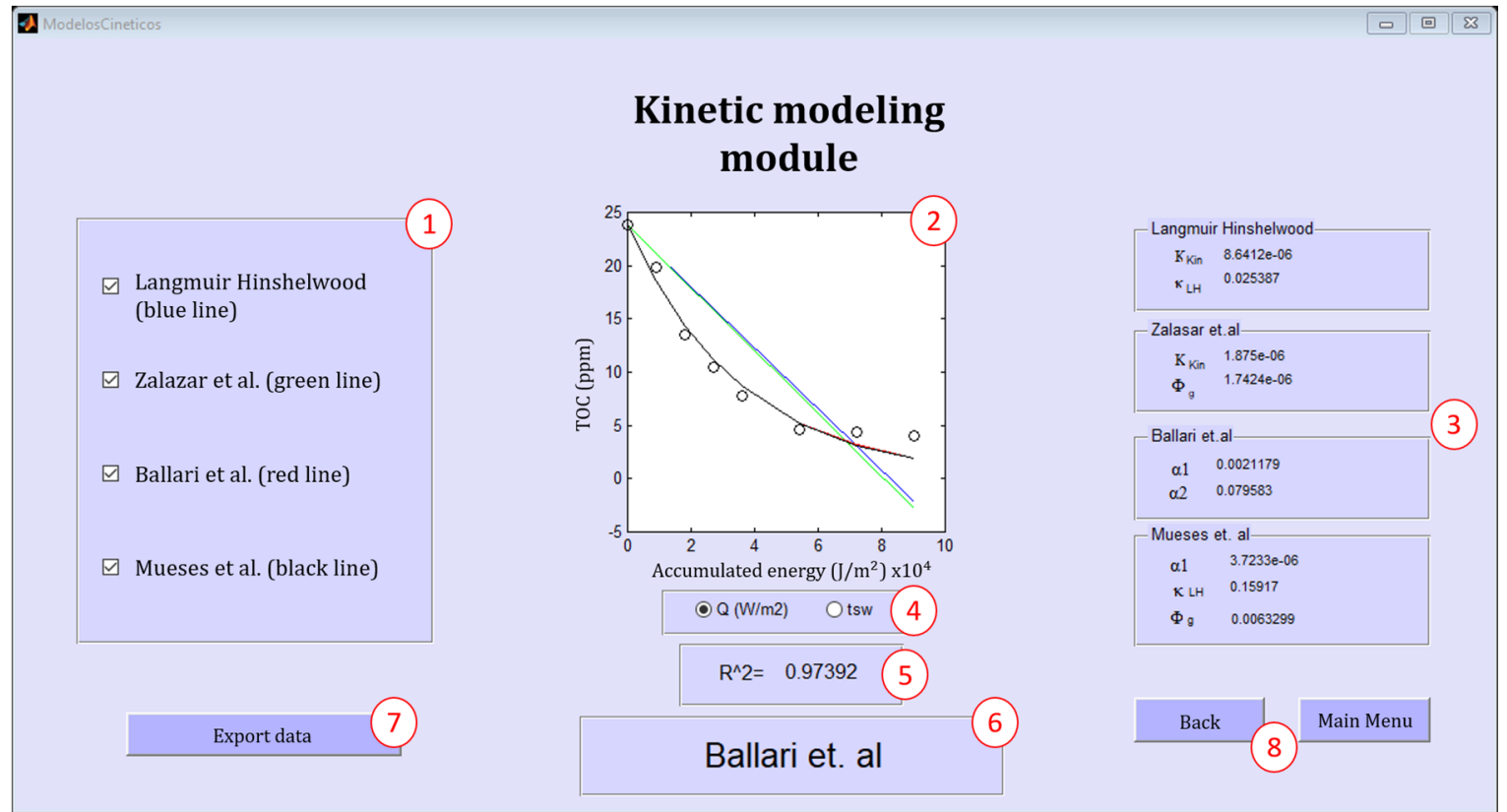

Figure 6. DCA fitting for the available kinetics models in the kinetics modeling module. (1) Kinetic models panel; (2) experimental data and models simulations plot; (3) fitted kinetic parameters panel; (4) $x$-axis magnitude panel; (5) correlation coefficient panel; (6) display of the kinetic model with the highest $R^{2}$ value among the ones selected; (7) export data button; (8) options menu panel.

\subsection{Example Case II: Solar Photodegradation of Methylene Blue in an OMTP}

In the previous example case, the user must provide all the required information to perform the computations. In this example, the use of the database incorporated in the PHOTOREAC kinetic modeling module is shown. Figure 7 shows the PHOTOREAC screen of the kinetic modeling module: (1) the photoreactor configuration panel, for selecting the photoreactor to be studied; (2) the model pollutant panel, for choosing the water contaminants from the five available options in the database; (3) the photocatalyst-pollutant panel, for choosing the photocatalyst concentration-initial pollutant concentration combination from the available options in the database; (4) the experimental data panel, for loading the pollutant concentration vs. accumulated energy (or standard time); (5) the system parameters panel, which displays the OVRPA and the $\beta=V_{R} / V_{T}$ factor charged.

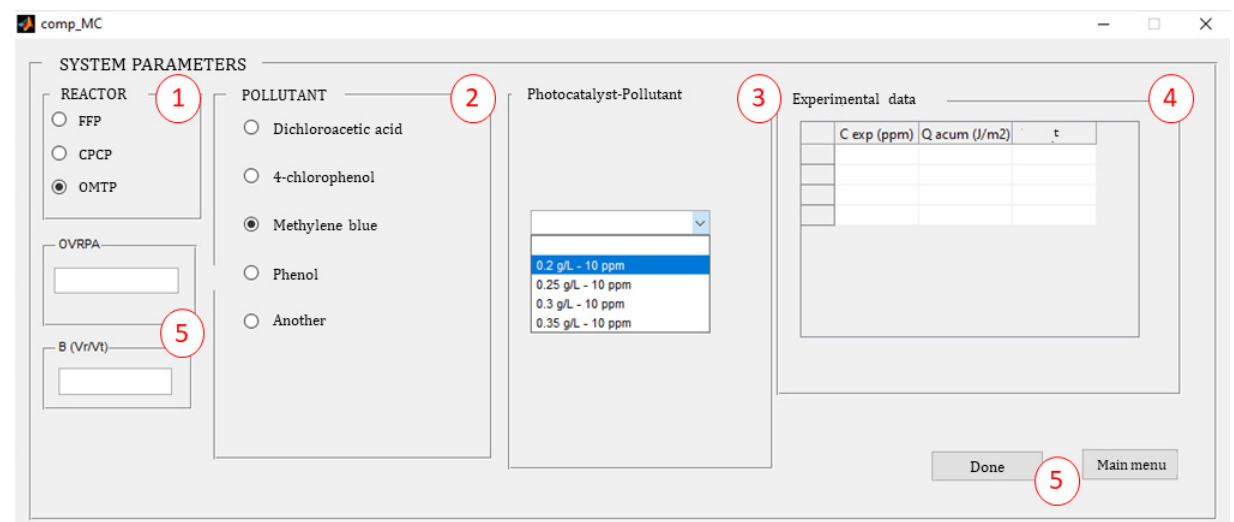

Figure 7. Database in the kinetic modeling module. (1) photoreactor configuration panel; (2) model pollutants panel; (3) photocatalyst-pollutant panel; (4) experimental data panel; (5) system parameters panel. 
In this case, an OMTP with methylene blue (MB) was selected as a model pollutant with an initial concentration of $C_{i}=10 \mathrm{ppm}$ and a photocatalyst concentration of $C_{c a t}=0.2 \mathrm{~g} / \mathrm{L}$. Figure 8 shows the results obtained by PHOTOREAC. It is observed that the best fitting is achieved for the Mueses et al. and Ballari et al. models with $R^{2}=0.99737$ for both. The other models reported $R^{2}=0.001$. As the Ballari et al. model is a particular case of the Mueses et al. model, the first is considered the more appropriate option since it is more specific for this case. These results agree with the discussion presented in the previous section.

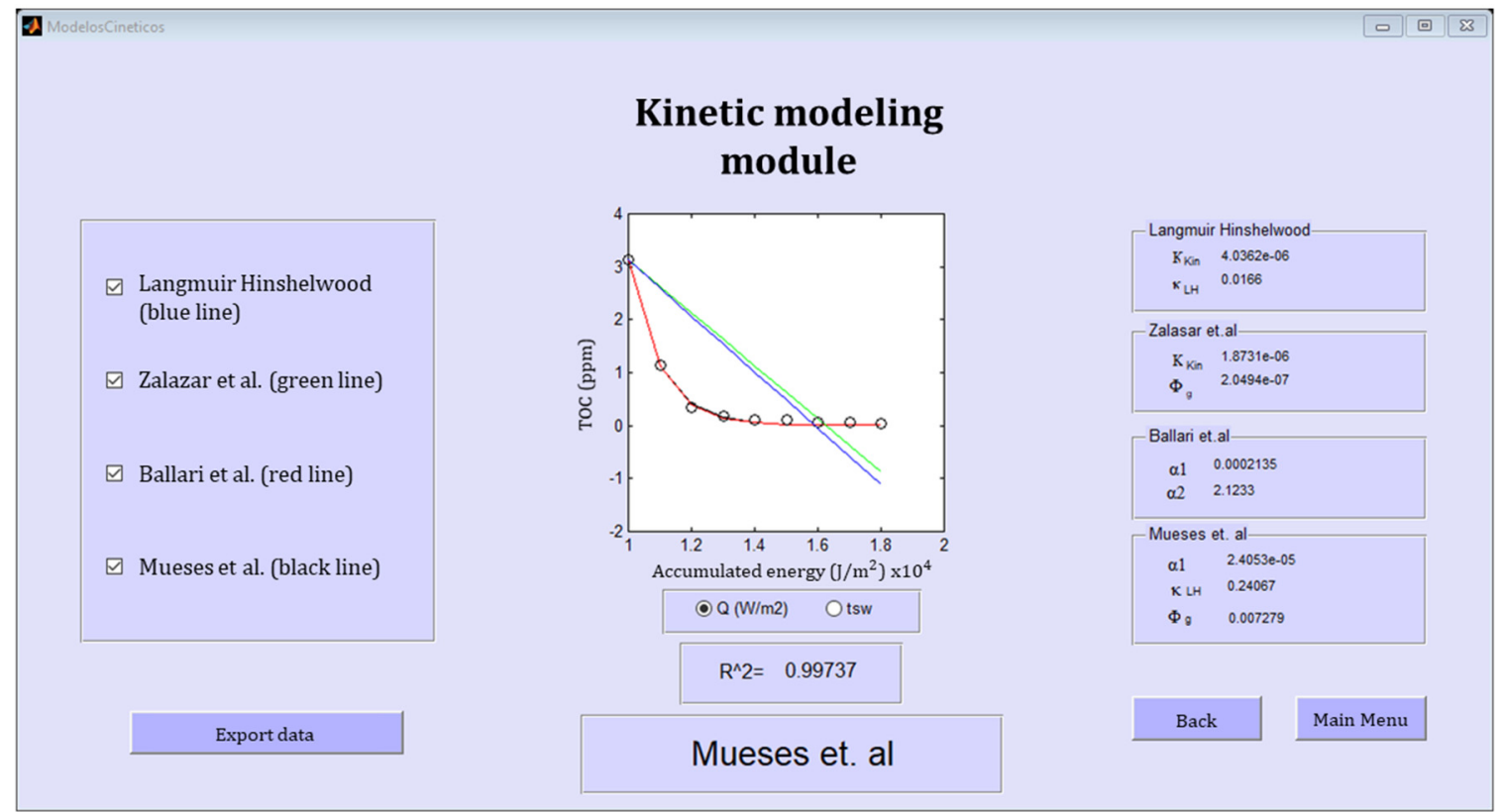

Figure 8. Methylene blue solar photodegradation fitting in an offset multi-tubular photoreactor (OMTP) for the four available kinetics models in the kinetic modeling module.

\subsection{Example Case III: Radiation Field Modeling in a Flat Plate Photoreactor (FPP)}

In this case, the objective was to compare the radiation field simulation for an FPP using SFM and SFM-HG. The photoreactor consists of a titled squared flat plate of length $L=1 \mathrm{~m}$, which is placed facing the sun and uniformly irradiated. A water film of $1 \mathrm{~cm}$ thickness flows over its surface, providing a reaction volume of $V_{R}=10 \mathrm{~L}$. The $\mathrm{TiO}_{2}$ P25 Evonik concentration is $C_{c a t}=0.2 \mathrm{~g} / \mathrm{L}$. Figures 9 and S1 show the LVRPA profile in the FPP calculated with the SFM-HG and the SFM, respectively. In both cases, the highest LVRPA values are found near to the surface of the water film (thickness $=0-0.2 \mathrm{~cm}$ ) because this is the boundary that the solar light irradiates. After $0.2 \mathrm{~cm}$, exponential decay in the LVRPA occurs as a result of the absorption and scattering of photons by the suspended photocatalyst. Due to the photoreactor being considered as uniformly irradiated, the changes in the LVRPA profile are only significant along with the water film thickness.

In Figure S1, which uses the SFM, a shaper exponential LVRPA profile is observed, with higher values near the irradiated boundary (at thickness $=0-0.2 \mathrm{~cm}$ ) when comparing to values in Figure 9, which uses the SFM-HG. These results are due to the difference in the scattering phase function; the SFM-HG uses a predominantly forward scattering phase function, which causes photons to penetrate deeper into the water film. By contrast, the SFM uses a predominantly backward phase function, which causes that photons to be redirected toward the irradiated boundary and be mostly absorbed in the beginning of the film or escape from the system [15]. 


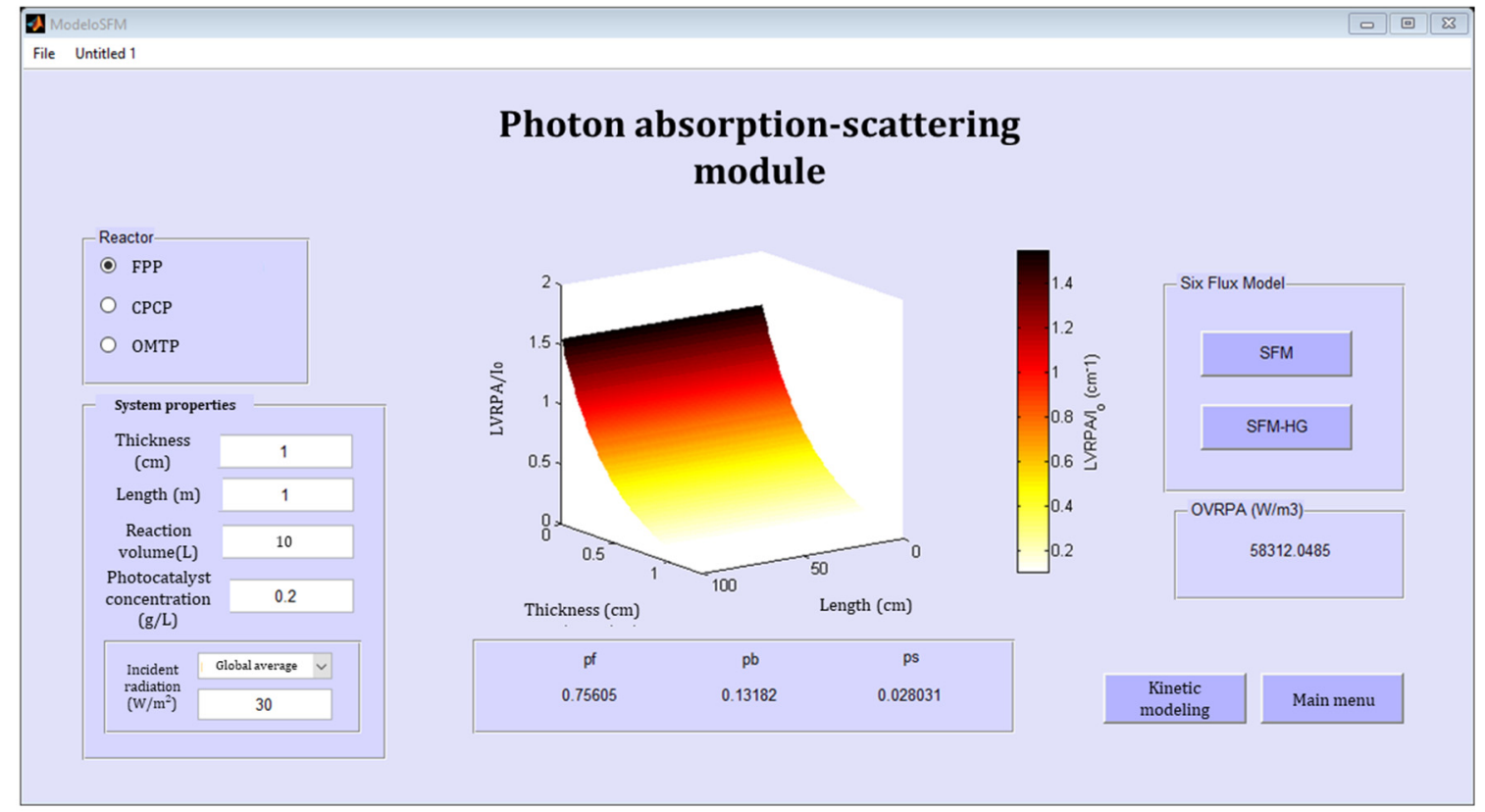

Figure 9. Radiation field simulation of a flat plate photoreactor (FPP) with SFM-HG.

\section{PHOTOREAC Implementation in Research Projects in Heterogeneous Photocatalysis and} Photoreactor Engineering by Chemical Engineering Undergraduates

Since the year 2015, different versions of PHOTOREAC have supported the final degree projects of chemical engineering students belonging to the Modeling and Applications of Advanced Oxidation Technologies Research Group at Cartagena University. The students developed research on heterogeneous photocatalysis and photoreactor engineering. A survey was done amongst them to determine the perceived impact of PHOTOREAC on their final degree projects. Table 4 shows the results of the survey. Between 2015-2018, ten final degree projects were developed in the research group, with an average impact of $37.5 \%$ perceived by the students. The use of PHOTOREAC can be summarized as follows: in four of the degree projects, both modules of PHOTOREAC were implemented since they performed the radiation field simulation and kinetic modeling of model pollutants; in two other projects, the photon-scattering module was used to determine the radiation field in photoreactors; finally, in four projects, the application was used in the learning process for modeling solar photoreactors. As a relevant outcome, two of the degree projects supported publications in high-impact journals. In all of the projects, the authors highlighted the use of PHOTOREAC as a user-friendly tool that allows them to reach the main objective of the projects or to achieve a fast advance in the learning curve, therefore allowing them to focus on more complex research.

Table 4. PHOTOREAC impact on final degree projects in chemical engineering.

\begin{tabular}{|c|c|c|c|c|}
\hline Year & $\begin{array}{c}\text { Title of the Final Degree } \\
\text { Project }\end{array}$ & $\begin{array}{c}\text { Related } \\
\text { Publication/Ref. }\end{array}$ & $\begin{array}{l}\text { PHOTOREAC } \\
\text { Impact on the } \\
\text { Project Perceived } \\
\text { by the Students }\end{array}$ & $\begin{array}{c}\text { PHOTOREAC } \\
\text { Implementation in the } \\
\text { Project }\end{array}$ \\
\hline 2015 & $\begin{array}{l}\text { Design and evaluation of a } \\
\text { modified compound parabolic } \\
\text { collector solar reactor }\end{array}$ & $\begin{array}{l}\text { A Novel Prototype } \\
\text { Offset Multi Tubular } \\
\text { Photoreactor (OMTP) for } \\
\text { solar photocatalytic } \\
\text { degradation of water } \\
\text { contaminants/ref. [10] }\end{array}$ & $30 \%$ & $\begin{array}{l}\text { Modeling the radiation } \\
\text { field and kinetics of } \\
\text { methylene blue for both } \\
\text { the CPCP and OMTP }\end{array}$ \\
\hline 2015 & $\begin{array}{l}\text { Effect of oxygen transfer from } \\
\text { the air on the photocatalytic } \\
\text { degradation of dichloroacetic } \\
\text { acid using a flat plate reactor }\end{array}$ & - & $50 \%$ & $\begin{array}{l}\text { Modeling the radiation } \\
\text { field and kinetics of } \\
\text { dichloroacetic acid in } \\
\text { an FFP }\end{array}$ \\
\hline
\end{tabular}


Table 4. Cont.

\begin{tabular}{|c|c|c|c|c|}
\hline Year & $\begin{array}{c}\text { Title of the Final Degree } \\
\text { Project }\end{array}$ & $\begin{array}{c}\text { Related } \\
\text { Publication/Ref. }\end{array}$ & $\begin{array}{l}\text { PHOTOREAC } \\
\text { Impact on the } \\
\text { Project Perceived } \\
\text { by the Students }\end{array}$ & $\begin{array}{l}\text { PHOTOREAC } \\
\text { Implementation in the } \\
\text { Project }\end{array}$ \\
\hline 2016 & $\begin{array}{l}\text { Radiant field modeling in } \\
\text { heterogeneous photoreactors } \\
\text { implementing Monte Carlo } \\
\text { simulation: Modification of } \\
\text { the Six Flux Model to new } \\
\text { phase functions }\end{array}$ & $\begin{array}{l}\text { Coupling the Six Flux } \\
\text { Absorption-Scattering } \\
\text { Model to the Henyey- } \\
\text { Greenstein scattering } \\
\text { phase function: } \\
\text { Evaluation and } \\
\text { optimization of radiation } \\
\text { absorption in solar } \\
\text { heterogeneous } \\
\text { photoreactors/ref. [15] }\end{array}$ & $60 \%$ & $\begin{array}{l}\text { Modeling the radiation } \\
\text { field for the FFP and a } \\
\text { CPCP }\end{array}$ \\
\hline 2016 & $\begin{array}{l}\text { Evaluation of the temperature } \\
\text { effect on the heterogeneous } \\
\text { photocatalytic degradation } \\
\text { kinetics }\end{array}$ & $\begin{array}{l}\text { Modeling and } \\
\text { experimental evaluation } \\
\text { of a non-isothermal } \\
\text { photocatalytic solar } \\
\text { reactor: temperature } \\
\text { effect on the reaction rate } \\
\text { kinetics/ref. [20] }\end{array}$ & $20 \%$ & $\begin{array}{l}\text { The learning process for } \\
\text { modeling CPCP }\end{array}$ \\
\hline 2016 & $\begin{array}{c}\text { Solar heterogeneous } \\
\text { photocatalytic degradation of } \\
\text { organic pollutants in a } \\
\text { pilot-scale modified tubular } \\
\text { collector }\end{array}$ & $\begin{array}{l}\text { A Novel Prototype } \\
\text { Offset Multi Tubular } \\
\text { Photoreactor (OMTP) for } \\
\text { solar photocatalytic } \\
\text { degradation of water } \\
\text { contaminants/ref. [10] }\end{array}$ & $50 \%$ & $\begin{array}{l}\text { Modeling the radiation } \\
\text { field and kinetics of } \\
\text { DCA, PH and 4-CP for } \\
\text { both the CPCP and } \\
\text { OMTP }\end{array}$ \\
\hline 2016 & $\begin{array}{l}\text { Simulation of in series and in } \\
\text { parallel arrangements of solar } \\
\text { reactors (CPCP) for } \\
\text { wastewater treatment }\end{array}$ & - & $30 \%$ & $\begin{array}{l}\text { The learning process for } \\
\text { modeling CPCP }\end{array}$ \\
\hline 2016 & $\begin{array}{l}\text { Experimental evaluation and } \\
\text { mathematical modeling of the } \\
\text { performance of } \mathrm{TiO}_{2}-\mathrm{P} 25 \text { reuse } \\
\text { in heterogeneous solar } \\
\text { photocatalytic degradation of } \\
\text { acetaminophen }\end{array}$ & - & $30 \%$ & $\begin{array}{l}\text { The learning process for } \\
\text { modeling СРCP }\end{array}$ \\
\hline 2017 & $\begin{array}{l}\text { Solar photocatalytic ozonation } \\
\text { applied to amoxicillin } \\
\text { degradation in wastewater at } \\
\text { pilot-plant scale }\end{array}$ & - & $30 \%$ & $\begin{array}{l}\text { The learning process for } \\
\text { modeling СРCP }\end{array}$ \\
\hline 2018 & $\begin{array}{l}\text { Mathematical modeling and } \\
\text { simulation of photocatalytic } \\
\text { hydrogen production }\end{array}$ & - & $35 \%$ & $\begin{array}{c}\text { Radiation field modeling } \\
\text { of an FFP }\end{array}$ \\
\hline 2018 & $\begin{array}{l}\text { Experimental evaluation and } \\
\text { mathematical modeling of the } \\
\text { regeneration of commercial } \\
\mathrm{TiO}_{2} \text { by the photocatalytic } \\
\text { degradation of glyphosate }\end{array}$ & - & $40 \%$ & $\begin{array}{l}\text { Modeling the radiation } \\
\text { field and the kinetics } \\
\text { glyphosate in a CPCP }\end{array}$ \\
\hline
\end{tabular}

\section{Analysis of the Overall Performance of PHOTOREAC}

PHOTOREAC was shown to be a useful tool for modeling and simulation of solar photoreactors, and in particular for a non-expert public. Its user-friendly interface developed in the graphical user interface of Matlab proved to be intuitive enough to be used successfully by chemical engineering undergraduates, which develop research in heterogeneous photocatalysis.

In Section 3, the application was evaluated for disparate operational conditions, showing that it can fit and simulate the photodegradation experimental data provided for the two cases evaluated: CPCP-DCA (example case I) and OMTP-MB (example case II). These example cases were very different from each other, mainly because of the different photoreactor geometries: $\mathrm{CPCP}$ can capture more 
solar radiation per length than the OMTP as a result of being equipped with reflectors. However, OMTP has more volume than the CPCP [10]. Additionally, the employed model pollutant, its initial concentration, and the photocatalyst concentration were different. In both examples, PHOTOREAC performed successfully, allowing the user to evaluate different kinetic expressions and extract relevant findings from it. Finally, example case III focused on the photon absorption-scattering module, in which the impact of the radiation model was evaluated and discussed for an FFP. In this case, PHOTOREAC shows its versatility for researchers with an interest in studying the energy absorption behaviors of photoreactors.

The dedicated interface of PHOTOREAC for photoreaction engineering, together with its numerical algorithm, allowed the evaluation of the performance of large scale solar photoreactors without time-consuming computations and a complex mathematical formulation. The time invested in preparing and launching a simulation in PHOTOREAC is between 5-10 min, and the calculation time does not exceed $45 \mathrm{~s}$. In contrast to commercial CFD simulators in which preparing and starting a first-time simulation may take a couple of hours needed for generating the photoreactor geometry in the system (or it importing it from CAD software), preparing the simulation modules and their models and selecting the proper meshing and numerical algorithms; besides, the computational time for each simulation is, generally, measured in hours [21-23]. Nevertheless, the results obtained by CFD simulators are much more complete and accurate than the results that PHOTOREAC may offer; for instance, CFD simulators provide detailed flow patterns for studying the hydrodynamics in the photoreactor. However, its high computational time may result in a barrier when exploring the impact of numerous parameters on a wide range of values.

Moreover, the most common CFD commercial simulators used in modeling photoreactors are very expensive licensed software. At the same time, PHOTOREAC is an open-access application that is available on-demand, by email to one of the authors of the paper, professor Miguel A. Mueses (mmueses@unicartagena.edu.co).

In conclusion, PHOTOREAC is recommended for the following cases: (i) for an introduction to photoreactor engineering; (ii) when a quantitative margin of error is still acceptable in the calculations; (iii) when qualitative results are the main objective of the work; and (iv) when the parametric space in the study is extensive, i.e., it is required to study the impact of numerous variables in broad ranges. In this case, PHOTOREAC may be employed to reduce the parametric space and then to implement a CFD simulator.

\section{Limitations and Future Work}

As with every modeling software, PHOTOREAC is limited by the availability and reliability of the input data provided by the users. Additionally, the computational application is limited to Titanium Dioxide P25 Evonik as photocatalyst. Although $\mathrm{TiO}_{2}$ P25 is the most common photocatalyst, the capability of performing simulations for any photocatalyst will be crucial for the software, since an area of intensive research in heterogeneous photocatalysis is the development and testing of new photoactive materials. On the other hand, expanding the available kinetic models would also be a considerable improvement, because it will allow users to make a more comprehensive analysis by comparing the results of the kinetic models' fitting. Moreover, it is necessary to implement the option that users introduces their own kinetic expression, since some pollutants will require concrete mathematical expression because their kinetic mechanism may not follow the most common postulates. These drawbacks are expected to be overcome in the upcoming version of PHOTOREAC.

In the authors' opinion, some important challenges for PHOTOREAC and, in general, for photoreaction engineering at the pilot-solar scale are that the models account for the variability of the incident radiation on the solar photoreactor caused by fluctuations in atmospheric conditions. This improvement will allow more accurate quantification of the energy absorbed by the suspended photocatalyst, and therefore better quantification of the chemical species produced by the photoactivation of the photocatalyst. 
Supplementary Materials: The following are available online at http://www.mdpi.com/2073-4441/12/8/2196/s1, Figure S1: Radiation field simulation of a flat plate photoreactor (FPP) with SFM.

Author Contributions: Conceptualization, B.C.-V., K.P.-G. and M.A.M.; data curation, B.C.-V., and K.P.-G.; formal analysis, R.A.-H.; funding acquisition, M.H.P.-C. and F.M.-M.; investigation, B.C.-V. and K.P.-G.; methodology, B.C.-V. and K.P.-G.; project administration, M.H.P.-C. and F.M.-M.; supervision, R.A.-H. and M.A.M.; validation, B.C.-V. and K.P.-G.; writing-original draft, R.A.-H.; writing—review and editing, R.A.-H., M.H.P.-C., M.A.M. and F.M.-M. All authors have read and agreed to the published version of the manuscript.

Funding: This research was funded by Universidad del Valle, grant number C.I. 21022.

Acknowledgments: The authors gratefully thank Universidad de Cartagena (Cartagena, Colombia) with the project 017-2018: "Plan de Fortalecimiento del Grupo de Investigación Modelado y Aplicación de Procesos Avanzados de Oxidación" and Universidad del Valle (Cali, Colombia) with the Project CI. 21022 "Estudio del efecto hidrodinámico y de transporte de energía radiante en el diseño y optimización de reactores fotocatalíticos heterogéneos solares. CI 21022." for financial support. Acosta-Herazo thanks the CEIBA foundation with the program "Bolivar Gana con Ciencia” for financing his doctoral studies.

Conflicts of Interest: The authors declare no conflict of interest.

\section{References}

1. Byrne, C.; Subramanian, G.; Pillai, S.C. Recent advances in photocatalysis for environmental applications. J. Environ. Chem. Eng. 2018, 6, 3531-3555. [CrossRef]

2. Kumaravel, V.; Mathew, S.; Bartlett, J.; Pillai, S.C. Photocatalytic hydrogen production using metal doped TiO2: A review of recent advances. Appl. Catal. B Environ. 2019, 244, 1021-1064. [CrossRef]

3. Spasiano, D.; Marotta, R.; Malato, S.; Fernandez-Ibañez, P.; Di Somma, I. Solar photocatalysis: Materials, reactors, some commercial, and pre-industrialized applications. A comprehensive approach. Appl. Catal. B Environ. 2015, 170-171, 90-123. [CrossRef]

4. Cassano, A.E.; Alfano, O.M. Reaction engineering of suspended solid heterogeneous photocatalytic reactors. Catal. Today 2000, 58, 167-197. [CrossRef]

5. Li Puma, G.; Brucato, A. Dimensionless analysis of slurry photocatalytic reactors using two-flux and six-flux radiation absorption-scattering models. Catal. Today 2007, 122, 78-90. [CrossRef]

6. Grčić, I.; Li Puma, G. Photocatalytic degradation of water contaminants in multiple photoreactors and evaluation of reaction kinetic constants independent of photon absorption, irradiance, reactor geometry, and hydrodynamics. Environ. Sci. Technol. 2013, 47, 13702-13711. [CrossRef]

7. Marugán, J.; van Grieken, R.; Pablos, C.; Satuf, M.L.; Cassano, A.E.; Alfano, O.M. Rigorous kinetic modelling with explicit radiation absorption effects of the photocatalytic inactivation of bacteria in water using suspended titanium dioxide. Appl. Catal. B Environ. 2011, 102, 404-416. [CrossRef]

8. Colina-Marquez, J.; Castilla-Caballero, D.; Machuca-Martinez, F. Modeling of a falling-film photocatalytic reactor: Fluid dynamics for turbulent regime. Appl. Math. Model. 2016, 40, 4812-4821. [CrossRef]

9. Malato, S.; Maldonado, M.I.; Fernández-Ibáñez, P.; Oller, I.; Polo, I.; Sánchez-Moreno, R. Decontamination and disinfection of water by solar photocatalysis: The pilot plants of the Plataforma Solar de Almeria. Mater. Sci. Semicond. Process. 2016, 42, 15-23. [CrossRef]

10. Ochoa-Gutiérrez, K.S.; Tabares-Aguilar, E.; Mueses, M.Á.; Machuca-Martínez, F.; Li Puma, G. A Novel Prototype Offset Multi Tubular Photoreactor (OMTP) for solar photocatalytic degradation of water contaminants. Chem. Eng. J. 2018, 341, 628-638. [CrossRef]

11. Manassero, A.; Satuf, M.L.; Alfano, O.M. Evaluation of UV and visible light activity of TiO2 catalysts for water remediation. Chem. Eng. J. 2013, 225, 378-386. [CrossRef]

12. Mueses, M.A.; Machuca-Martinez, F.; Li Puma, G. Effective quantum yield and reaction rate model for evaluation of photocatalytic degradation of water contaminants in heterogeneous pilot-scale solar photoreactors. Chem. Eng. J. 2013, 215-216, 937-947. [CrossRef]

13. Colina-Márquez, J.; Machuca-Martínez, F.; Li Puma, G. Photocatalytic mineralization of commercial herbicides in a pilot-scale solar CPC reactor: Photoreactor modeling and reaction kinetics constants independent of radiation field. Environ. Sci. Technol. 2009, 43, 8953-8960. [CrossRef] [PubMed]

14. Colina-Marquez, J.; Machuca-Martínez, F.; Puma, G.L. Radiation absorption and optimization of solar photocatalytic reactors for environmental applications. Environ. Sci. Technol. 2010, 44, 5112-5120. [CrossRef] [PubMed] 
15. Acosta-Herazo, R.; Monterroza-Romero, J.; Mueses, M.A.; Machuca-Martínez, F.; Li Puma, G. Coupling the Six Flux Absorption-Scattering Model to the Henyey-Greenstein scattering phase function: Evaluation and optimization of radiation absorption in solar heterogeneous photoreactors. Chem. Eng. J. 2016, 302, 86-96. [CrossRef]

16. Otálvaro-Marín, H.L.; Mueses, M.A.; Machuca-Martínez, F. Boundary layer of photon absorption applied to heterogeneous photocatalytic solar flat plate reactor design. Int. J. Photoenergy 2014, 2014. [CrossRef]

17. Zalazar, C.S.; Romero, R.L.; Martín, C.A.; Cassano, A.E. Photocatalytic intrinsic reaction kinetics I: Mineralization of dichloroacetic acid. Chem. Eng. Sci. 2005, 60, 5240-5254. [CrossRef]

18. De Los Ballari, M.M.; Alfano, O.O.; Cassano, A.E. Photocatalytic degradation of dichloroacetic acid. A kinetic study with a mechanistically based reaction model. Ind. Eng. Chem. Res. 2009, 48, 1847-1858. [CrossRef]

19. Otálvaro-Marín, H.L.; González-Caicedo, F.; Arce-Sarria, A.; Mueses, M.A.; Crittenden, J.C.; Machuca-Martinez, F. Scaling-up a heterogeneous H2O2/TiO2/solar-radiation system using the DamkÖhler number. Chem. Eng. J. 2019, 364, 244-256. [CrossRef]

20. Molano, M.; Mueses, M.A.; Fiderman, M.M. Modelado y evaluación experimental de un reactor solar fotocatalítico no isotérmico: Efecto de la temperatura sobre la cinética de la velocidad de reacción. Ing. Compet. 2017, 19, 143-154. [CrossRef]

21. Casado, C.; García-Gil, Á.; van Grieken, R.; Marugán, J. Critical role of the light spectrum on the simulation of solar photocatalytic reactors. Appl. Catal. B Environ. 2019, 252, 1-9. [CrossRef]

22. Casado, C.; Marugán, J.; Timmers, R.; Muñoz, M.; van Grieken, R. Comprehensive multiphysics modeling of photocatalytic processes by computational fluid dynamics based on intrinsic kinetic parameters determined in a differential photoreactor. Chem. Eng. J. 2017, 310, 368-380. [CrossRef]

23. Boyjoo, Y.; Ang, M.; Pareek, V. Some aspects of photocatalytic reactor modeling using computational fluid dynamics. Chem. Eng. Sci. 2013, 101, 764-784. [CrossRef]

(C) 2020 by the authors. Licensee MDPI, Basel, Switzerland. This article is an open access article distributed under the terms and conditions of the Creative Commons Attribution (CC BY) license (http://creativecommons.org/licenses/by/4.0/). 